\title{
On the Reversal Effects of the Velocity Quotient on the Directions of Changes of Finishing Results of Conventional and Flexible Grinding
}

\author{
Zdzislaw Pluta, Tadeusz Hryniewicz \\ Politechnika Koszalinska, Mechanical Engineering Department, Koszalin, Poland \\ E-mail: Tadeusz.Hryniewicz@tu.koszalin.pl \\ Received September 30, 2011; revised November 3, 2011; accepted November 10, 2011
}

\begin{abstract}
The paper presents the problem of right direction of changes of the velocity quotient in view of getting advantageous smoothing results of material finishing using a compact elastic wheel. In fact the problem has been considered reversely in comparison with the change direction of the velocity quotient on the grounds of knowledge on grinding using ceramic wheels. The specifics of performance of the elastic wheels are considered. The investigation was carried out on the effect of their peripheral velocity on the directions of smoothing. The problem is considered by presenting it on the background of determined results of grinding using a ceramic wheel. The dependence of a determined roughness measure of the smoothed surface on the velocity quotient is delivered. The forms of a function approximating experimental dependences of the subject roughness measure on the mentioned quotient have been derived. Furthermore, the results coming out of the performed experimental studies have been presented.
\end{abstract}

Keywords: Elastic Grinding Wheel, Peripheral Velocity, Velocity Quotient, Measure of Surface Roughness, Potential Field, Potential Band, Nominal Quotient Constant, Real Quotient Constant

\section{Introduction and Problem Presentation}

The elastic grinding wheels, as indicated e.g. in one of the book literature [1], belong to special abrasive tools. They possess specific features which evidently differenttiate them among other tools used to abrasive machining. The subject grinding wheels do not produce an effect on the workpiece in geometric-kinematic way as it is observed e.g. during grinding using ceramic wheels. The surface smoothing with the elastic wheels takes place in the dynamic action with the dynamics having relatively ordered character. It results from the manner of grains fixation and their displacement in the wheel structure. Contrary to these compact elastic grinding wheels, other elastic tools (for instance, flaky disks or buffing wheels) may smooth the material with manifold increased and less ordered dynamics. The strew/pour tools (for instance, the abrasive tapes/belts) also allow to perform with a relatively ordered dynamics but in the degree respecttively lesser than the elastic wheels. These former tools allow the working abrasive grains to be displaced one against another, and in consequence, for more harmoni- ous cooperation during the material machining.

The process of surface finishing with elastic wheels is dynamized advantageously. The treatment is intensified by the unstable zone of this tool which contacts the machined material. The abrasive grains are not there in such an energetic state as they are on the free peripheral surface of the grinding wheel behind the machining zone. Here the energetic states may be tentative only when the change of the kind of variable motion occurs (for instance, retarded-accelerated, and reverse: accelerated-retarded).

Here is the generally described performance of an elastic wheel, presented mainly in the work [2]. The abrasive grains of the near-surface peripheral layer come in contact with the workpiece and with this loose their kinematic energy, moving further (in the machining zone) with a variable motion against itself, machined surface and the nominal trajectory. Such a turbulent flux of abrasive grains moves through the whole machining zone, then coming back to its primary energetic state, regaining the primary kinematic energy. Pulsating under machining, the grains change the primary surface structure, making 
it more advantageous from the viewpoint of expected technological requirements. The claims of improvement of the surface roughness and the growth of gloss of surface are the most important.

In contact with the machined workpiece the abrasive grains decrease their inertia and centrifugal reaction whereas the elasticity of their fixations may change not only quantitatively, but also qualitatively. The bond, first extended, attempts to return to the zero state, and at the greater in-feeds may even undergo the compression. The grains in this zone perform the work which is non-behavioral, because their firm energetic states are not preserved.

That is the specifics of performance of the compact elastic grinding wheels, manufactured by many companies of abrasive manufacture profile [3-8]. It would be useful and advantageous to present the subject abrasive tools in view of revealing some essential differences between the performance of elastic and rigid (ceramic) grinding wheels. The reference to the ceramic wheel will be still necessary. Of course, that provided the comparative analysis is to be concerned on the influence of peripheral velocity on the determined machining effects.

To reveal the essential problem it is worthy comparing the two totally different ways of abrasive machining: grinding and finishing/smoothing, i.e. the machining of material with a rigid wheel (usually ceramic), and a compact elastic wheel. The technology of grinding using a ceramic wheel is generally known. However, it is worthy noting a comparative criterion that is the peripheral velocity of wheel and its influence on the finishing results of the treatment which is the surface roughness.

It is known that with the increase of peripheral velocity of ceramic grinding wheel the roughness of the machined surface decreases, respectively; it has been presented in the literature [9-11]. It is connected, as explained in the work [12], with the decrease of thickness of the layer cut by a single edge and the increasing amount of heat in the machining zone, and with this the temperature of elements of the machining system. The work [13] adds that then the grains loading decreases, and with this the grinding wheel performs as more hard. The consequence of such a performance of the wheel is longer work of its grains, which is less frequency of its spalling. Together with the increase of peripheral velocity of the grinding wheel, as mentioned above, the frequency of the grain contact with the machined material is greater, whereas the time of this contact is lesser, respecttively.

These advantageous conditions, favouring the decrease of roughness, are illustrated by a plot (Figure 1) excerpted from the reference [12], being the image of the dependence of the surface unevenness height (created by

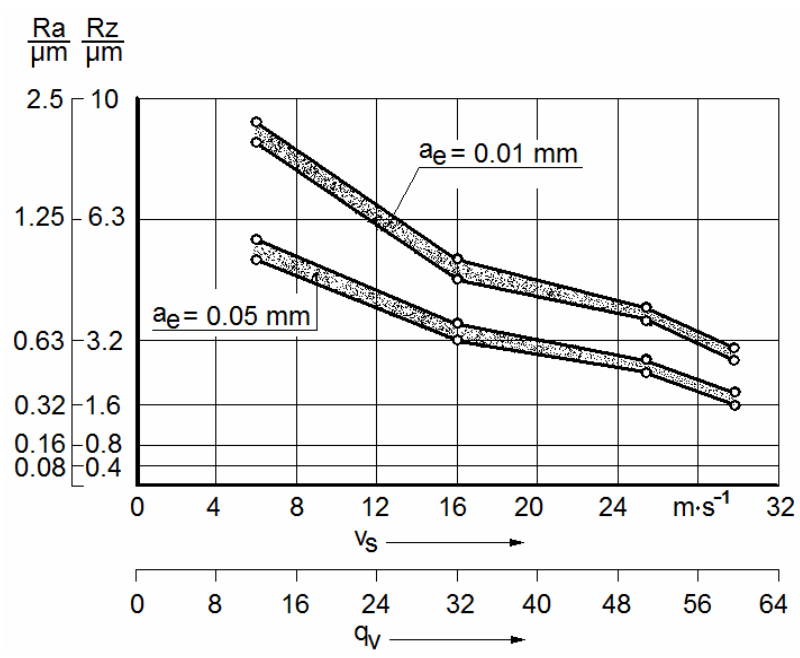

Figure 1. Dependence of measures $R_{a}, R_{z}$ of surface roughness (formed by a material grinding) on the velocity quotient $q_{v}$ and the peripheral velocity $v_{s}$ of grinding wheel [12].

the material grinding) on the peripheral velocity of the grinding wheel, that is $R_{z}=f\left(v_{s}\right)$. The same curve relates also with the dependence of arithmetic mean of the profile deviation of the mean line, that is $R_{a}$, on the velocity quotient $q_{v}$, so the ratio of the peripheral velocity $v_{s}$ of the grinding wheel to the peripheral velocity $v_{p}$ of the ground workpiece. Concerning this, the plot covers also the coordinates axes, related to the mentioned magnitudes.

The hardened manganese steel $(\mathrm{C}=0.5 \%, \mathrm{Mn}=1 \%)$ was used as a ground material. The tool was the grinding wheel of the grain size No. 46 made of semi-precious aloxite 97A. The peripheral velocity of the ground workpiece was assumed $v_{p}=30 \mathrm{~m} \cdot \mathrm{min}^{-1}$, and the longitudinal feed $a_{p}=0.3 H=12 \mathrm{~mm} \cdot \mathrm{rev}^{-1}$, where $H$ is the width of the wheels. There were two values of depth $a_{e}$ of the grinding wheel penetration in the machined material: 0.01 and $0.05 \mathrm{~mm}$.

Of course, that range of variability of the peripheral velocity of grinding wheel does not exhaust the kinematic possibilities of the wheel at all. Here the upper limit of the variability interval of this parameter was caused by the shattering effect of the wheel (its resistance to disrupture). Under other conditions the wheels rotate with the velocities $v_{s}$ equal: $100 \mathrm{~m} \cdot \mathrm{s}^{-1}$ [9], and even $320 \mathrm{~m} \cdot \mathrm{s}^{-1}$ [10]. Furthermore, that kinematic parameter results from the given resistance criterion of the tool with both of them being correlated positively: the greater strength of the wheel to disrupture (shattering), the higher its peripheral velocity.

Moreover, taking into account the finishing/smoothness criterion one should note the wheel should operate 
with the highest possible velocity. Here both the roughness and the velocity are correlated negatively. That means the increase in peripheral velocity of the wheel results in the decrease of roughness of the newly created surface. Thus, to obtain the advantageous surface results the highest possible peripheral velocity should be provided to the grinding wheel. That is the so called the gold rule of grinding.

The quest of connection of surface roughness with the peripheral velocity of the grinding wheel (also the velocity quotient) is then determined univocally and used in practice; however, the relations of these magnitudes referred to the compact elastic wheels have not been assumed and/or used until now. Then it is worthy presenting first the history of usage of these grinding wheels, together with the outline of their development and studies over the influence of the peripheral velocity of this type of tools on the directions of changes of the finishing results of smoothing.

To solve the problem, first the history of usage of the compact elastic wheels and the effect of their peripheral velocity on the directions of changes of the finishing results of treatment, are delivered. Those special abrasive tools, covering one of many manufactured geometric assortments, are made in Poland by the Fabryka Tarcz Ściernych in Grodzisk Mazowiecki [5]; their production was begun in 1973. There were only some foreign companies, such as SLIP-NAXOS [3], ARTIFEX [4], KLINGSPOR [6], and LUKAS [7] which started to do it earlier. These tools contain the abrasive grains displaced in the entire mass of the resin bond, so they are compact tools.

The work [14] treats on polishing using the single crystals of silicon by the elastic aloxite grinding wheels. The way of manufacture of that kind of wheels has been also described. The process of their manufacture consisted of the following stages: mixing the polyurethane and abrasive grains; smearing the mixture over the steel base plate creating the layer of thickness of about $15 \mathrm{~mm}$; leaving such prepared abrasive-polyurethane material for 3 - 4 days for the chemical reactions to occur. It is worthy mentioning that the Polish literature $[15,16]$ treats in extension on the manufacture of the polyurethane elastic abrasive tools.

The journal "Werkstatt und Betrieb" covers the results of finishing of the steel SW18 and the brass MO59 by means of elastic wheels of the properly differentiated characteristics [17], as well as the results of cutting materials using flexibly fixed grains of the post-copper slag [18]. "Schleifen und Trennen" presents some aspects of manufacture and usage of the grinding wheels of porous elastic wheels [19].

It is worthy turning the attention on the work [11], published by the journal "Maschinen und Werkzeug". Based on the example of the grinding wheels of Artifex the advantages of abrasive tools on the elastic bond (of the flexibility detected even on touch), have been discussed. It was stated that the use of these wheels requires the relative high rotational velocities especially in relation to the grinding pins (diameters of 5 to $30 \mathrm{~mm}$ ). It is treated about a high cutting output of which the performance is achieved at not a big compression force and the tool velocity, equaling up to $30 \mathrm{~m} \cdot \mathrm{s}^{-1}$.

On the world edition market the problems of finishing using the compact elastic wheels has been noted only in recent decade. At the beginning of this decade (2001) a work appeared treating of the curvilinear finishing of surfaces using the grinding pins of a special design [20]. The concept, structure, shape, and the manufacture procedure of the susceptible abrasive tool made of thermosetting polyurethane elastomer coated with abrasive material of aluminum oxide, have been discussed there. This tool enables the finishing treatment thanks to the ability to deform and conforming the shape of the machined surface in the machining zone. The following effects were studied, such as: obtained surface roughness, the mentioned machining effectiveness and durability in the process of treatment of high-alloy tool steel, previously machined by milling.

Then the work [21] appeared, concerned with elastic properties of the flexible abrasive tools of polyurethane bonds. There the results of the studies of the wheel properties with the outline of their modification in view of increasing the effectiveness of the process of abrasive smoothing have been presented.

Recently, in 2009, the works [22,23] appeared. The article [22] presents first the characteristics of the initial conditions, relating to the peripheral smoothing using elastic wheels. These conditions are determined by the incision angle, depending on the peripheral velocity of the grinding wheel, in-feed, and the workpiece velocity. Such a determined dependence was used to forecast the directions of roughness changes. It was stated, based on the results of experimental verification of the prognoses, that the finishing results of the peripheral smoothing may be anticipated with a success, making use of the mentioned prognosis indicator.

The work [23] explains much wider those initial conditions of cutting. It has been proved that one cannot smooth a material using a rotating wheel with a critical velocity, which the velocity is connected with the wheel resistance to disrupture. The wheel velocity has to be respectively lower, because in that case the effect of the grain size on the surface roughness is significantly less, and moreover it affects advantageously the finishing results of the smoothing. 
The history of usage of the elastic grinding wheels indicates they were exploited quite variably. There were three directions of activities concerned with their exploitation when non-uniform rules were used. It was about the direction of value changes of the peripheral velocity of those tools. The history of using the compact elastic wheels considered in this aspect requires including also Polish literature to the analysis. In that case the picture will be complex in character.

At first the smoothing process was realized with the peripheral velocity denoted on the elastic grinding wheel, not changing it in any value direction (of course that velocity was decreased itself, resulting from the wheel wear during the process of smoothing). One has to add that the mentioned peripheral velocity refers to the strength of the wheel to disrupture or the shattering. Such an approach to the kinematics of smoothing has been treated e.g. by the works $[15,19]$. The work [11] testifies that the kinematic rule is still in force concerning the smoothing technology, none the less it is unjust from the viewpoint of main, the most important criterion of the estimation of the grinding wheel cuttability, i.e. the results of this machining.

Furthermore, there were the attempts to interfere in the exploitational characteristics of the wheel, creating such conditions of its fixation to allow operating the wheel with the increased peripheral velocity $[24,25]$. The activities were focused onto elaboration of the proper ways of fixation of the wheels. It was also taken into account that the elastic wheel during its work should have the possibility to a considerable freedom of changes of the geometric form. It is to avoid the creation of non-advantageous 3D states of stresses.

A further considerable increase of the peripheral velocity of the wheel was possible by its fixation from the external side of the peripheral surface $[26,27]$. That way a new non-conventional kind of abrasive smoothing was created, where the internal surface (hole) became the active working surface of the wheel.

In reference to the external peripheral smoothing (classical smoothing) none of these two mentioned directions of activities ensured a decrease of roughness of the machined surface. That time the thing was set on head, going in a reverse direction, radically decreasing the peripheral velocity of the wheel. It appeared that very advantageous smoothing results were obtained. They are discussed in such exemplary works like $[22,23,28,30]$.

The history of using the compact elastic grinding wheels testifies the ways leading to the best solutions cannot be determined in advance. Such is the nature of the cognitive activities. The problem is because the subject elastic wheels are the tools of a specific structure. The presented descriptions indicate it has not been taken into account in a sufficient degree at determining the effect of the tool velocity on the finishing results. This is why that primary improper direction of the cognition took place.

In the next section that essential thread of the work, concerning the effect of the velocity quotient on the finishing results of peripheral smoothing, is to be presented in detail. That will make it possible to compare that characteristics with the earlier one (see Figure 1), regarding the grinding.

\section{Dependence of the Roughness Measure of Machined Surface on the Velocity Quotient}

That title characteristics (Figure 2) has been created basing on the study results excerpted from the works $[2,22,30]$.

They are the study results of the effect of machining

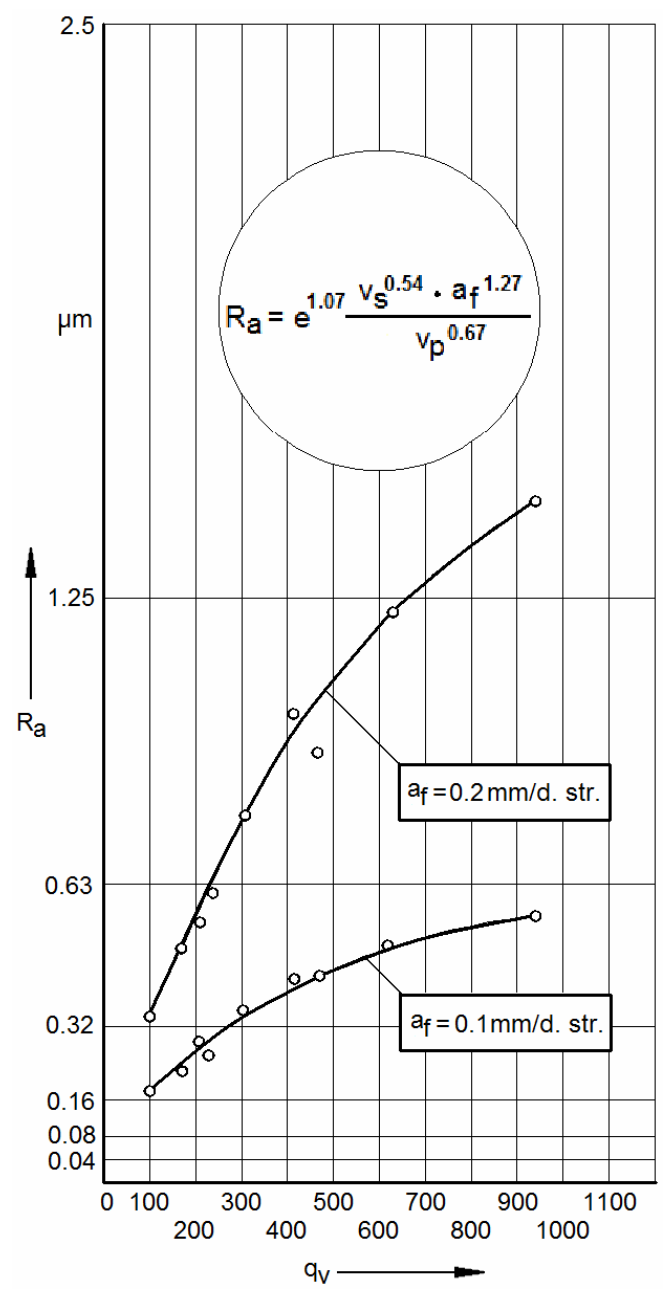

Figure 2. Dependence of measure of the smoothed surface on the velocity quotient for two different in-feeds. 
parameters on the surface roughness machined by the grinding wheels of porous elastic bonds. The experiments were performed in the conditions of plunge/indepth smoothing of flat surface that is without a crossfeed. The electrolytic copper, containing in its chemical contents minimum $99.9 \% \mathrm{Cu}$, designated as $\mathrm{Cu} 99.9 \mathrm{E}$ and the feature M1E, was the machined material. The flat semi-elastic grinding wheels T1A P of the bond BPE, containing the grains of aloxite $99 \mathrm{~A}$ of number 46 , were used, that is

\section{T1A $125 \times 20 \times 20 \quad 99 \mathrm{~A} \quad 46 \mathrm{P} \quad \mathrm{BPE}$}

The wheel velocity $v_{s}$, longitudinal feed $v_{p}$ and the in-feed $a_{f}$ are contained in the following intervals closed on both sides: $\langle 31.5 ; 14\rangle,\langle 8 ; 2\rangle,\langle 0.4 ; 0.1\rangle$, with the units corresponding to: $\mathrm{m} / \mathrm{s}, \mathrm{m} / \mathrm{min}, \mathrm{mm} / \mathrm{d} \cdot \mathrm{str}$., respectively. The assumed in the studies the kind of smoothing excludes one of the machining parameters, namely the cross-feed. The number of passages $i_{p}=5$ was assumed as a constant.

Through a proper statistic elaboration of the study results, after performing the whole related procedure, the following empirical (statistic-experimental) formula was obtained:

$$
R_{a}=\mathrm{e}^{1.07} \frac{v_{s}^{0.54} \cdot a_{f}^{1.27}}{v_{p}^{0.67}}
$$

with the parameter $R_{a}$ (the mean arithmetic profile deviation from the mean line) expressed by the unit in $[\mu \mathrm{m}]$. The units of the remaining magnitudes, for which the Formula (1) fulfills its role, are as follows: $v_{s}[\mathrm{~m} / \mathrm{s}]$, $a_{f}[\mathrm{~mm}], v_{p}[\mathrm{~m} / \mathrm{min}]$, respectively.

One should note that the measure of surface roughness, that is $R_{a}$, was determined here for $a_{f}=0.1 ; 0.2 \mathrm{~mm} /$ $\mathrm{d} \cdot \mathrm{str}$. The peripheral velocity of the wheel assumed the following values: $14 ; 21$; and $31.5 \mathrm{~m} / \mathrm{s}$. That third machining parameter, which is the longitudinal feed $v_{p}$ had the following values: $2 ; 4$; and $8 \mathrm{~m} / \mathrm{min}$.

Therefore, there were nine different values of the velocity quotients $q_{v}$ obtained, that is the ratio of the velocities of the grinding wheel $v_{s}$ to the longitudinal feed $v_{p}$. Thus, $q_{v}=105 ; 157.5 ; 210 ; 236.25 ; 315 ; 420$; $427.5 ; 630 ; 945$. Of course the same units are related to, namely $[\mathrm{m} / \mathrm{s}]$. The measurement results $R_{a}$ of the smoothed surface for the whole these values of the quotient $q_{v}$ are presented in Table 1.

It is worthy noting that these two systems of experimental points are displaced in the way that the line relating with the exponential and degressively rising functions may be drawn. That may be described analytically to obtain a result determined by a physical formula. That new formula is to possess a physical sense, being not an empirical (statistic-experimental) formula, without such
Table 1. Measurement results of roughness measure of the smoothed surface.

\begin{tabular}{cccc}
\hline & & \multicolumn{2}{c}{$a_{f}, \mathrm{~mm} / \mathrm{d} \cdot \mathrm{str}}$. \\
\cline { 3 - 4 } No. & $q_{v}$ & 0.1 & 0.2 \\
\cline { 3 - 4 } & & 0.175 & 0.37 \\
\cline { 3 - 4 } 1 & 105 & 0.21 & 0.49 \\
2 & 157.5 & 0.28 & 0.53 \\
3 & 210 & 0.245 & 0.60 \\
4 & 236.25 & 0.35 & 0.77 \\
5 & 315 & 0.42 & 0.98 \\
6 & 420 & 0.42 & 0.91 \\
7 & 427.5 & 0.49 & 1.19 \\
8 & 630 & 0.56 & 1.47 \\
9 & 945 & &
\end{tabular}

a sense.

Furthermore, first a general and then detailed description of this kind of curve, which then could approximate those sets of experimental points, should be presented.

\section{Derivation of the Form of Function Approximating Experimental Dependence of the Subject Roughness Measure on the Velocity Quotient}

That dependence may be created without any problem, however, under one condition. To do this, the whole space of changes of the roughness measure, regarding first of all the initial conditions of the process, should be related to and considered. That question, so essential, has been related to in the literature $[2,22,23,31]$. Indeed, the initial conditions regarded the surface finishing using elastic grinding wheels $[2,22,23]$, concerning generally the tool life under cut [31], but the essence of it is analogous and should be related to the description of any process or phenomenon.

At the very source, one should take advantage of the primary, general form of differential equation, describing any phenomena or processes, occurring in fact with variable, non-linearly variable velocity. Of course, it is about the velocity (rate), not a speed (vector magnitude); the velocity being the intensity (gradient) of changes of the considered magnitude, being a scalar magnitude, and here, not connected with time.

The mentioned source differential equation [2] has the following form:

$$
\mathrm{d} Z= \pm \frac{\partial Z}{\partial N} \mathrm{~d} N
$$

where $\mathrm{d} Z$ - total differential of dependent variable, $\mathrm{d} N$ total differential of independent variable, $\partial N-$ partial derivative of dependent variable, referred to the indepen- 
dent variable. The signs $( \pm)$ are the algebraic operators, fulfilling a determined role. The sign $(+)$ has a formal meaning, just confirming the physical sense of the determined dependence. The sign $(-)$ ascribes such a sense to a determined record.

For the considered variables the Formula (2) has the following form:

$$
\mathrm{d} R_{a}= \pm \frac{\partial R_{a}}{\partial q_{v}}
$$

because the dependent variable is $R_{a}$, and the independent variable $q_{v}$.

Now this dependence should be integrated on both sides, remembering that the total differential is the state function. Furthermore, that requires the determination of states, i.e. the limits of integrating: bottom and top.

The scheme of creation of the adequate description of the dependence $R_{a}=f\left(q_{v}\right)$ is presented in Figure 3, showing all elements of this process of reasoning. The curve illustrating that dependence comes out of an initial point of coordinates $0, R_{a}^{0}$, and then it proceeds exponentially and degressively rising. It completes its real course in the point 1 , where the process of smoothing using a determined grinding elastic wheel has its end.

Thus one should take into consideration both the beginning and the end of variability intervals of the dependent variable $R_{a}$ and independent one $q_{v}$. These limits of both of the mentioned variables have their physical meaning concerned with the studied technological system. The initial point corresponds with the zero peripheral velocity of the wheel, which is the parameter $R_{a}^{0}$ as the measure of roughness of the surface smoothed by the motionless grinding wheel. The final point of the curve refers to the neuralgic machining situation, while the wheel operates on the limit of the resistance to disrupture. Therefore, further work of the wheel, above the terminal velocity, is impossible.

Here the quantum nature of the described system may be noticed. A part of the system has been revealed; behind the limits, for a determined elastic wheel, that system does not exist. That example proves the macro-reality has also such a quantum nature. The literature [31] provides further examples confirming that nature. There the analytical quantum changes of the tool life under cut,

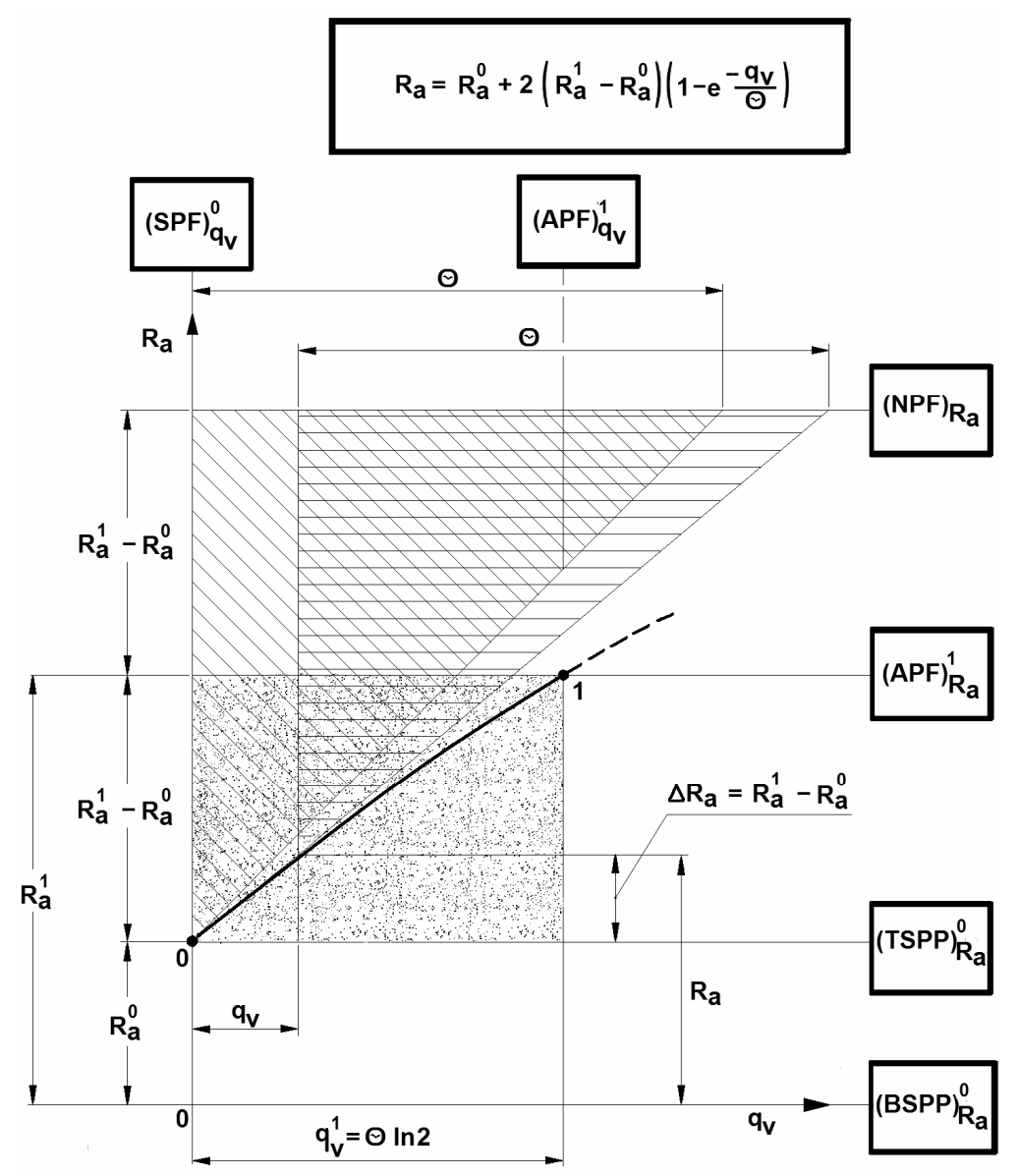

Figure 3. Indicatrix of dependence of the roughness measure $R_{a}$ on the velocity quotient $q_{v}$. 
the changes dependent on the main velocity, being the tool or the workpiece velocities, have been presented.

The mentioned limits, concerning the studied technological system, are the potential fields. These fields are situated on two directions; one of them is the direction of changes of the parameter $R_{a}$, whereas the second one is the direction of changes of the velocity quotient, that is $q_{v}$. On the first direction there are: bottom roughness stable potential field $(B S P F)_{R_{a}}^{0}$, top roughness stable potential field $(T S P F)_{R_{a}}^{0}$, roughness unstable potential field $(A P F)_{R_{a}}^{1}$, and the nominal roughness potential field $(N P F)_{R_{a}}$. On the second direction there are the following fields: quotient stable potential field $(S P F)_{q_{v}}^{0}$, quotient unstable potential field $(A P F)_{q_{v}}^{1}$. Between the fields $(B S P F)_{R_{a}}^{0}$ and $(T S P F)_{R_{a}}^{0}$ there is a potential band. The fields $(T S P F)_{R_{a}}^{0},(A P F)_{R_{a}}^{1}$, and $(S P F)_{q_{v}}^{0}$ and $(A P F)_{q_{v}}^{1}$ delimit the interstate space (dotted area), where the exponential and degressively rising changes of the parameter $R_{a}$ take place.

The curve of roughness measure, comprised between the points $0-1$, is the envelope of the right-angled triangles, moving with its horizontal leg on the nominal potential field $(N P F)_{R_{a}}$; with the horizontal leg being invariable and equal to the nominal quotient constant $\Theta$, and the vertical leg changing respectively, decreasing with the displacing triangle in the direction of the velocity quotient. That nominal field is situated symmetrically against the level of the end of the described system, on the distance equal the length of the real space-time in the direction of the surface roughness measure.

Therefore over the real (proper) space there is an improper space situated, where the curve (dashed line) approaches towards the asymptote, being the mentioned potential field. This creation forms an auxiliary design, required to the description of the real curve, reflecting the adequate dependence of $R_{a}$ on $q_{v}$.

Now one may begin to integrate the Equation (3), and in fact only one of its version, regarding the sign $(-)$; it concerns the analyzed course of the parameter $R_{a}$, that is the course indeed exponential, but rising degressively, where the increments of the studied roughness parameter decrease, respectively. Therefore

$$
\mathrm{d} R_{a}=-\frac{\partial R_{a}}{\partial q_{v}} \mathrm{~d} q_{v}
$$

By integrating the Equation (4), one has to denote the limits of integrals of the total differentials. That means

$$
\int_{R_{a}^{0}+\Delta R_{a}}^{R_{a}^{1}+\left(R_{a}^{1}-R_{a}^{0}\right)} \mathrm{d} R_{a}=-\frac{\partial R_{a}}{\partial q_{v}} \int_{q_{v}}^{q_{v}+\Theta} \mathrm{d} q_{v}
$$

and further

$$
2\left(R_{a}^{1}-R_{a}^{0}\right)-\Delta R_{a}=-\frac{\mathrm{d} R_{a}}{\mathrm{~d} q_{v}} \Theta
$$

or

$$
\frac{\mathrm{d} R_{a}}{2\left(R_{a}^{1}-R_{a}^{0}\right)-\Delta R_{a}}=-\frac{1}{\Theta} \mathrm{d} q_{v}
$$

One may notice the partial derivative has been substituted by the quotient of the regular total differentials. It could be done that way as the regular total differentials have been distinctly determined by introducing the limits of their integrals.

Furthermore, by intergrating both sides of the Equation (7), one obtains the result

$$
\ln \left[2\left(R_{a}^{1}-R_{a}^{0}\right)-\Delta R_{a}\right]=-\frac{1}{\Theta} q_{v}+C^{*}
$$

that is

$$
2\left(R_{a}^{1}-R_{a}^{0}\right)-\Delta R_{a}=\mathrm{e}^{-\frac{q_{v}}{\Theta}+C^{*}}=\mathrm{e}^{C^{*}} \cdot \mathrm{e}^{-\frac{q_{v}}{\Theta}}=C \mathrm{e}^{-\frac{q_{v}}{\Theta}}
$$

After taking into account that for $q_{v}=0$ the magnitude $\Delta R_{a}=0$, one obtains

$$
C=2\left(R_{a}^{1}-R_{a}^{0}\right)
$$

and after substituting (10) to (9), and then, regarding $\Delta R_{a}=R_{a}-R_{a}^{0}$

$$
R_{a}=R_{a}^{0}+2\left(R_{a}^{1}-R_{a}^{0}\right) \cdot\left(1-\mathrm{e}^{-\frac{q_{v}}{\Theta}}\right)
$$

Now one may determine the second coordinate of the point 1 , that is $q_{v}^{1}$. It is obtained by introducing the parameter $R_{a}^{1}$ and the mentioned coordinate $q_{v}^{1}$ to the Equation (11).

Thus

$$
q_{v}^{1}=\Theta \ln 2
$$

and

$$
\Theta=\frac{q_{v}^{1}}{\ln 2}
$$

Therefore the Equation (11) is determined mathematically for $q_{v} \in\langle 0,+\infty\rangle$, whereas physically for

$q_{v} \in\left\langle 0, q_{v}^{1}\right\rangle$. Furthermore, however, that equation is not adjusted to the practical usage because it contains a nominal quotient constant; placed on the nominal field, being the asymptote, with that improper (mathematic) 
part of the curve of the parameter $R_{a}$ approaching it. It should be expressed as a function of its real quotient constant $\Theta^{*}$. That dependence may be derived by taking advantage of the scheme (Figure 4).

From the Thales of Milesios theorem the following proportion results

$$
\frac{\Theta}{2\left(R_{a}^{1}-R_{a}^{0}\right)}=\frac{\Theta^{*}}{R_{a}^{1}-R_{a}^{0}}
$$

so

$$
\Theta=2 \Theta^{*}
$$

and

$$
\Theta^{*}=\frac{\Theta}{2}
$$

and after regarding the dependence (13)

$$
\Theta^{*}=\frac{q_{v}^{1}}{2 \ln 2}
$$

and

$$
q_{v}^{1}=2 \Theta^{*} \ln 2
$$

Thus, after substituting (15) to (11), one obtains

$$
R_{a}=R_{a}^{0}+2\left(R_{a}^{1}-R_{a}^{0}\right) \cdot\left(1-\mathrm{e}^{-\frac{q_{v}}{2 \Theta^{*}}}\right)
$$

And then the equation is adjusted to the real space, where the adequate characteristics of the studied system exist.

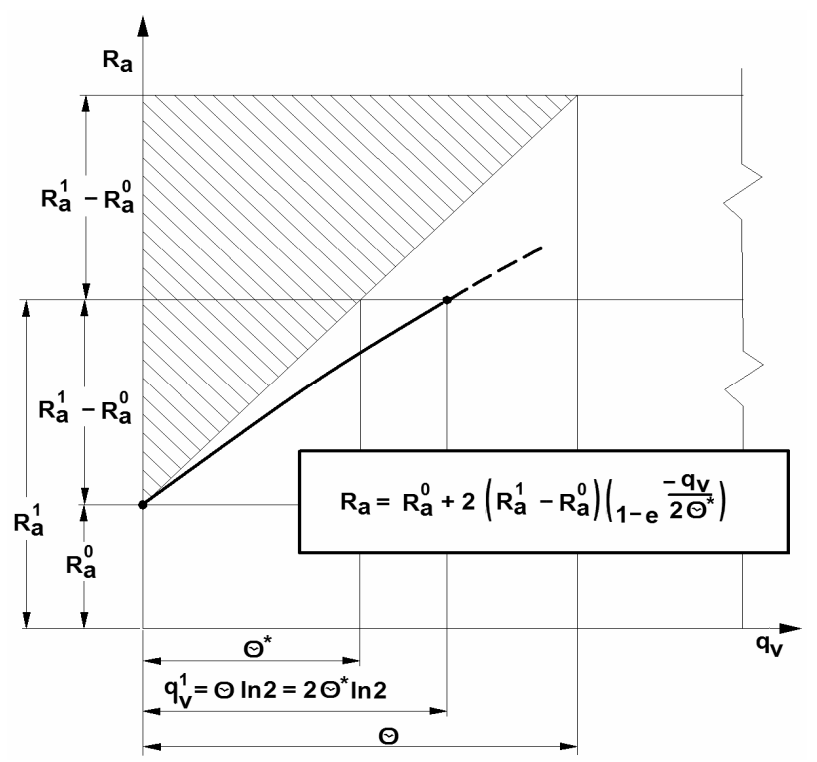

Figure 4. Auxiliary scheme to the derivation of dependence between the nominal $\Theta$ and real $\Theta^{*}$ quotient constant.

\section{Statistic Elaboration of Results of Experimental Studies}

Taking advantage of the presented theory, first of all one should determine the values of coordinates $q_{v}^{*}$, with the coordinates determining the position of the straight line, tangent to the searched, adequate course of the parameter $R_{a}$. These coordinates result from the Formula (17), then

$$
q_{v}^{*}=\frac{q_{v}^{1}}{2 \ln 2}
$$

The calculation results of these coordinates (Table 2) indicate that they are lower in values than the experimental coordinates.

The values $q_{v}^{*}$ should be now elaborated statistically by approximating them according to the dependence

$$
R_{a}=R_{a}^{0}+k_{0} q_{v}^{*}
$$

where the symbol $k_{0}$ denotes the initial coefficient of intensity (rate) of the increment $R_{a}$, that is the surface roughness measure (mean arithmetic profile deviation from the mean line). That coefficient is with the same the first derivative of the function $R_{a}=f\left(q_{v}\right)$ for $q_{v}=0$, then

$$
k_{0}=\left(\frac{\mathrm{d} R_{a}}{\mathrm{~d} q_{v}}\right)_{q_{v}=0}
$$

For the general written linear dependence of this type

\begin{tabular}{|c|c|c|c|c|c|}
\hline \multirow{3}{*}{$R_{a}, \mu \mathrm{m}$} & \multirow{2}{*}{\multicolumn{2}{|c|}{$\frac{a_{f}, \mathrm{~mm} / \mathrm{d} \cdot \mathrm{str} .}{0.1}$}} & \multirow{3}{*}{$R_{a}, \mu \mathrm{m}$} & \multirow{2}{*}{\multicolumn{2}{|c|}{$\frac{a_{f}, \mathrm{~mm} / \mathrm{d} \cdot \mathrm{str} .}{0.2}$}} \\
\hline & & & & & \\
\hline & $q_{v}$ & $q_{v}^{*}$ & & $q_{v}$ & $q_{v}^{*}$ \\
\hline 0.175 & 105 & 76 & 0.37 & 105 & 76 \\
\hline 0.21 & 157.5 & 113 & 0.49 & 157.5 & 113 \\
\hline 0.28 & 210 & 151 & 0.53 & 210 & 151 \\
\hline 0.245 & 236.25 & 170 & 0.60 & 236.25 & 170 \\
\hline 0.35 & 315 & 227 & 0.77 & 315 & 227 \\
\hline 0.42 & 420 & 302 & 0.98 & 420 & 302 \\
\hline 0.42 & 427.5 & 308 & 0.91 & 427.5 & 308 \\
\hline 0.49 & 630 & 453 & 1.19 & 630 & 453 \\
\hline 0.56 & 945 & 680 & 1.47 & 945 & 680 \\
\hline
\end{tabular}

$$
y=a+b x
$$

the coefficients $a$ and $b$ are determined according to the following formulae:

$$
b=\frac{n \sum_{i=1}^{n} x_{i} y_{i}-\sum_{i=1}^{n} x_{i} \sum_{i=1}^{n} y_{i}}{n \sum_{i=1}^{n}\left(x_{i}\right)^{2}-\left(\sum_{i=1}^{n} x_{i}\right)^{2}}
$$

Table 2. Results of measurements and calculations of the magnitude characterizing the studied technological reality. 


$$
a=\frac{1}{n}\left(\sum_{i=1}^{n} y_{i}-b \sum_{i=1}^{n} x_{i}\right)
$$

with the formulae being the result of using the rule of the least sum of the deviations squares of experimental and theoretical values, resulting from the position of linear regression function. That rule is described in detail in the literature, e.g. [32-35].

The comparison of the magnitudes needed to calculate the values of the coefficients of the linear regression: initial roughness parameter $R_{a}^{0}$ and the initial coefficient of intensity (rate) of the increment of $R_{a}$ in the Formula (21) is presented in Table 3.

The coefficient is described by the following formulae:

$$
\begin{gathered}
k_{0}=\frac{n \sum_{i=1}^{n}\left(q_{v}^{*}\right)_{i}\left(R_{a}\right)_{i}-\sum_{i=1}^{n}\left(q_{v}^{*}\right)_{i} \sum_{i=1}^{n}\left(R_{a}\right)_{i}}{n \sum_{i=1}^{n}\left(q_{v}^{*}\right)_{i}^{2}-\left[\sum_{i=1}^{n}\left(q_{v}^{*}\right)_{i}\right]^{2}} \\
R_{a}^{0}=\frac{1}{n}\left[\sum_{i=1}^{n}\left(R_{a}\right)_{i}-k_{0} \sum_{i=1}^{n}\left(q_{v}^{*}\right)_{i}\right]
\end{gathered}
$$

Thus for $a_{f}=0.1 \mathrm{~mm} / \mathrm{d} \cdot \mathrm{str}$.

$$
\begin{aligned}
& k_{0}=\frac{9 \times 1059.38-2480 \times 3.15}{9 \times 975452-(2480)^{2}}=6.55 \times 10^{-4} \mu \mathrm{m} \\
& R_{a}^{0}=\frac{1}{9}\left(3.15-6.55 \times 10^{-4} \times 2480\right)=0.17 \mu \mathrm{m}
\end{aligned}
$$

Therefore

$$
R_{a}=0.17+6.55 \times 10^{-4} q_{v}^{*}
$$

By substituting the terminal limit value of $R_{a}$, that is $0.56 \mu \mathrm{m}$ to the Equation (30), one obtains $q_{v}^{*}=\Theta^{*}=595$. Thus $\Theta=2 \cdot 595=1190$, that results from the Formula (15). The dependence (11) may be now presented in the quantitative form, by introducing the values $R_{a}^{0}=0.17 \mu \mathrm{m}, R_{a}^{1}=0.56 \mu \mathrm{m}$, and $\Theta=595$ to it. Therefore

$$
R_{a}=0.17+0.78\left(1-e^{-\frac{q_{v}}{1190}}\right)
$$

That has been also presented graphically (Figure 5). That is a quantitative dependence of the roughness measure $R_{a}$ on the velocity quotient $q_{v}$ for the in-feed $a_{f}=0.1 \mathrm{~mm} / \mathrm{d} \cdot \mathrm{str}$.

Furthermore, for $a_{f}=0.2 \mathrm{~mm} / \mathrm{d} \cdot \mathrm{str}$.

$$
\begin{gathered}
k_{0}=\frac{9 \times 2555.22-2480 \times 731}{9 \times 975452-(2480)^{2}}=18.52 \times 10^{-4} \mu \mathrm{m} \\
R_{a}^{0}=\frac{1}{9}\left(7.31-18.52 \times 10^{-4} \times 2480\right)=0.30 \mu \mathrm{m}
\end{gathered}
$$

Therefore

\begin{tabular}{|c|c|c|c|c|c|c|c|c|}
\hline \multirow{3}{*}{$i$} & \multirow{3}{*}{$\left(R_{a}\right)_{i}, \mu \mathrm{m}$} & \multicolumn{3}{|c|}{$a_{f}, \mathrm{~mm} / \mathrm{d} \cdot \mathrm{str}$} & \multirow{3}{*}{$\left(R_{a}\right)_{i}, \mu \mathrm{m}$} & \multicolumn{3}{|c|}{$a_{f}, \mathrm{~mm} / \mathrm{d} \cdot \mathrm{str}$} \\
\hline & & \multicolumn{3}{|c|}{0.1} & & \multicolumn{3}{|c|}{0.2} \\
\hline & & $\left(q_{v}^{*}\right)_{i}$ & $\left(q_{v}^{*}\right)_{i}^{2}$ & $\left(q_{v}^{*}\right)_{i}-\left(R_{a}\right)_{i}$ & & $\left(q_{v}^{*}\right)_{i}$ & $\left(q_{v}^{*}\right)_{i}^{2}$ & $\left(q_{v}^{*}\right)_{i}-\left(R_{a}\right)_{i}$ \\
\hline 1 & 0.175 & 76 & 5776 & 13.30 & 0.37 & 76 & 5776 & 28.12 \\
\hline 2 & 0.21 & 113 & 12769 & 23.73 & 0.49 & 113 & 12769 & 55.37 \\
\hline 3 & 0.28 & 151 & 22801 & 42.28 & 0.53 & 151 & 22801 & 80.03 \\
\hline 4 & 0.245 & 170 & 28900 & 41.65 & 0.60 & 170 & 28900 & 102.00 \\
\hline 5 & 0.35 & 227 & 51529 & 79.45 & 0.77 & 227 & 51529 & 174.79 \\
\hline 6 & 0.42 & 302 & 91204 & 126.84 & 0.98 & 302 & 91204 & 295.96 \\
\hline 7 & 0.42 & 308 & 94864 & 129.36 & 0.91 & 308 & 94864 & 280.28 \\
\hline 8 & 0.49 & 453 & 205209 & 221.97 & 1.19 & 453 & 205209 & 539.07 \\
\hline 9 & 0.26 & 380 & 462400 & 380.80 & 1.47 & 680 & 462400 & 999.60 \\
\hline$\Sigma$ & 3.15 & 2480 & 975452 & 1059.38 & 7.31 & 2480 & 975452 & 2555.22 \\
\hline
\end{tabular}

$$
R_{a}=0.30+18.52 \times 10^{-4} q_{v}^{*}
$$

By substituting the terminal limit value of $R_{a}$, that is $1.47 \mu \mathrm{m}$ to the Equation (34), one obtains $q_{v}^{*}=\Theta^{*}=632$. Thus $\Theta=2 \cdot 632=1264$, that results from the Formula (15). The dependence (11) may be now presented in the quantitative form, by introducing the

Table 3. Comparison of magnitudes needed to calculate the values of coefficients of linear regression. 


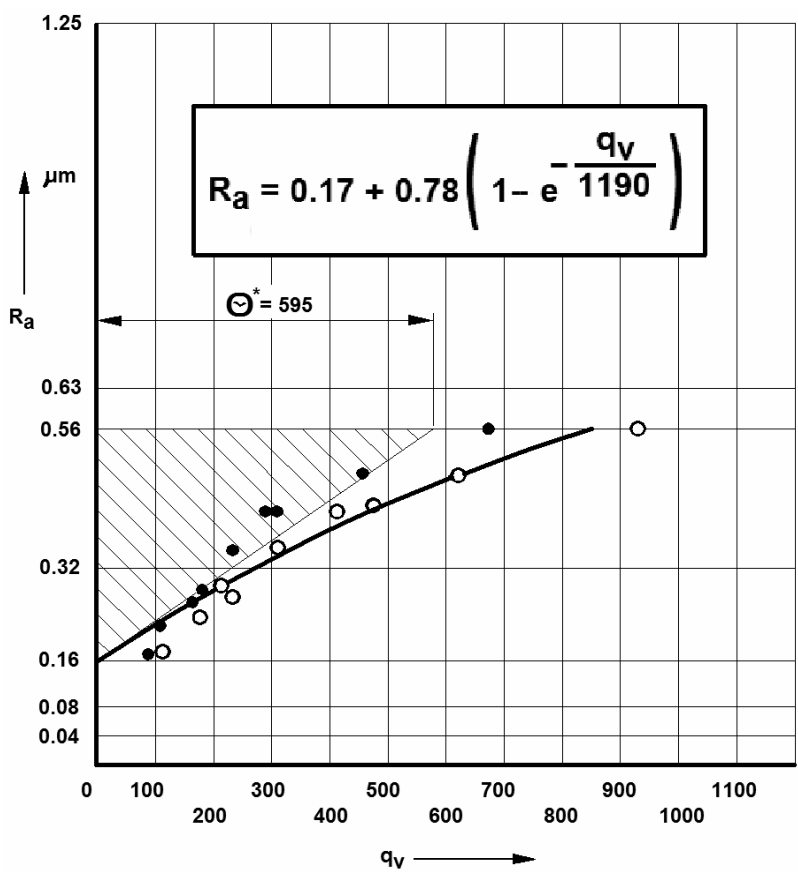

Figure 5. Dependence of roughness measure $R_{a}$ on the velocity quotient $q_{v}$ for the in-feed $a_{f}=0.1 \mathrm{~mm} / \mathrm{d} \cdot \mathrm{str}$.

values $R_{a}^{0}=0.30 \mu \mathrm{m}, R_{a}^{1}=1.47 \mu \mathrm{m}$, and $\Theta=1264$ to it. Therefore

$$
R_{a}=0.30+2.34\left(1-\mathrm{e}^{-\frac{q_{v}}{1264}}\right)
$$

That has been also presented graphically (Figure 6). That is a quantitative dependence of the roughness measure $R_{a}$ on the velocity quotient $q_{v}$ for the in-feed $a_{f}=0.2 \mathrm{~mm} / \mathrm{d} \cdot \mathrm{str}$.

\section{Summary}

It results from the presented material the rules of using of the compact elastic grinding wheels are not the same, congruent to the rules relating to the rational exploitation of the ceramic wheels. These rules are in fact reversal and cannot be a criticless copy of the rules of grinding using the mentioned ceramic wheels. It is important not to follow the groundless technological imitation, relying on the equality of the two operations: smoothing/flexible grinding and a conventional grinding.

Thus, as it has been indicated, to obtain the advantageous finishing results by machining using the elastic grinding wheel, the possibly least values of the velocity quotient should be used; contrary to the grinding using a ceramic wheel where the direction of the value changes of this parameter should be reversal. That is quite a valuable observation; knowing that it is not necessary to

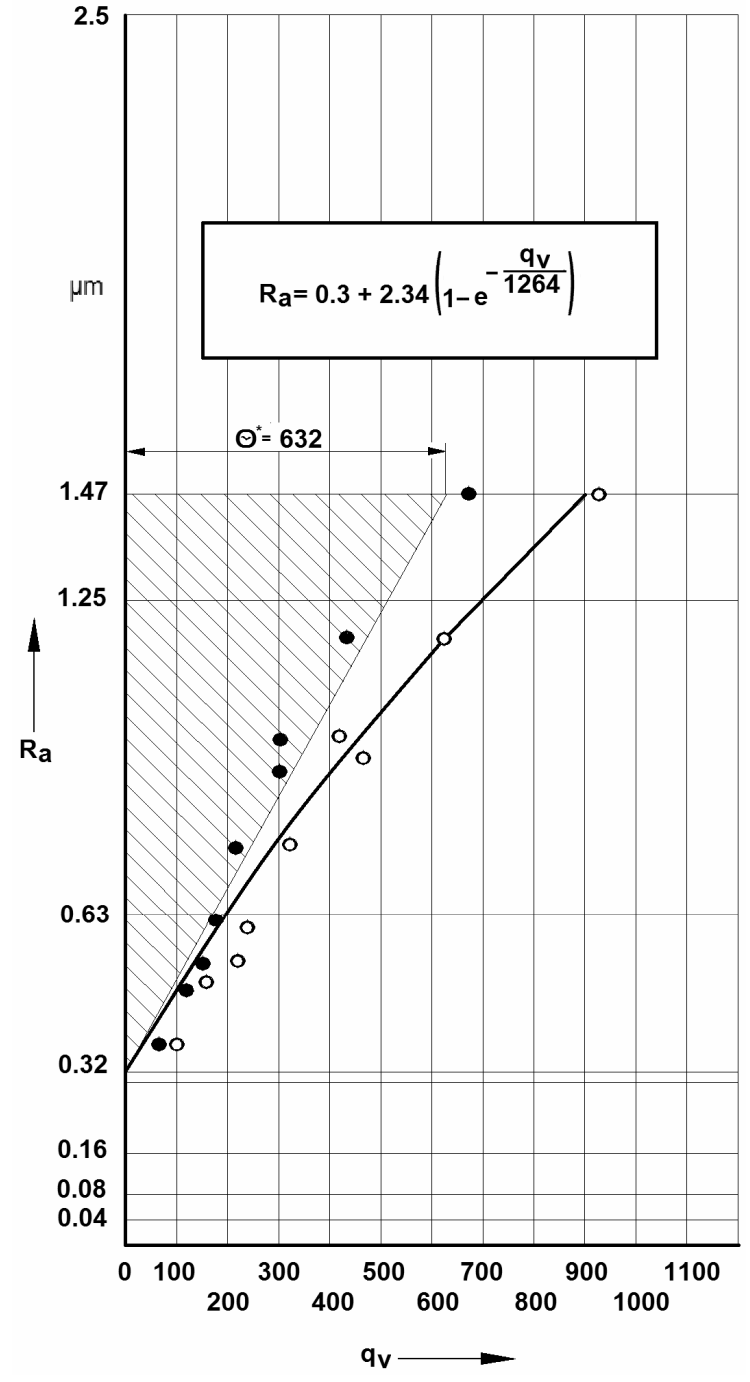

Figure 6. Dependence of roughness measure $R_{a}$ on the velocity quotient $q_{v}$ for the in-feed $a_{f}=0.2 \mathrm{~mm} / \mathrm{d} \cdot \mathrm{str}$.

manufacture the elastic wheels of such numerous and differentiated sizes of the abrasive grain. The effect of the size of this component of the wheel is essential only in case of grinding using the ceramic wheels.

It is worthy underlining the presented and completely solved the quest of elaboration of the experimental material, the sets of points of the coordinates being the velocity quotient and a determined surface roughness measure, respectively. The introduced quantitative dependences have a physical meaning which is their essential attribute.

That type of courses, degressively rising, are characteristic for many different systems; they have no analytical and uniform physical description. The courses do not possess a separate interval of the physical definition, turning towards the asymptote, and that is possible only 
in mathematics.

There are some new achievements of the presented work. Firstly, it is the quantitative approach to the effect of velocity quotient on the roughness measure of machined surface. Thus commonly used parabolic regression, relying on substitution of the multiple experimental points has been abandoned. It was discovered that a significant decrease of velocity quotient leads to the essential influencing roughness of the treated material. Moreover, the presented model may have a broader application.

It results that the presented here the method of elaboration of sets of experimental points, with the system indicating their exponential and degreessively rising course, may be used with a success to the approximation of experimental material, characterizing also other phenomena or processes.

\section{References}

[1] M. Rodziewicz, "Mechanical Polishing of Metals," WNT, Warszawa, 1968.

[2] Z. Pluta, "Fundamentals of Surface Smoothing Using Eleasic Grinding Wheels," Wydawnictwo Politechniki Koszalińskiej, Koszalin, 2007.

[3] “' Soft' Grinding Wheel for Polishing and Micro-Chips Removal," Prospectus of SLIP-NAXOS, 2000.

[4] "Elastic Grinding Wheels," Catalogue of ARTIFEX, 1999.

[5] "Elastic Polishing Wheels," Prospectus of Grinding Wheels Manufacture of Grodzisk Mazowiecki, Poland, 1998.

[6] "Programme of Kronem-R-Flex Abrasives," Prospectus of KLINGSPOR, 2001.

[7] “Grinding and Polishing," Catalogue of LUKAS, 2002.

[8] "Systems of Abrasive Materials. Delivery Programme," Catalogue of 3M, 1997.

[9] T. Sierżant, E. Weiss and Z. Weiss, "Selected Problems of High-Speed Grinding," Biuletyn Techniczny, Vol. 19, No. 9-10, 1975, pp. 109-114.

[10] F. I. Klocke, "High-Speed Grinding Fundamentals and State of the Art in Europe, Japan and the USA," Annals of the CIRP, Vol. 46, No. 2, 1977, pp. 715-724.

[11] "Grinding with Elastic Bond. High Peripheral Velocities Favour Effectiveness of Machining," Maschinen und Werkzeug, Vol. 100, No. 1-2, 1999, pp. 44-45.

[12] J. Kaczmarek, "Fundamentals of Chip, Abrasive, and Erosive Treatment," WNT, Warszawa, 1970.

[13] L. Burnat, "Grinding and Superfinish of Metals," WNT, Warszawa, 1962.

[14] M. Kieda, A. Hamada and S. Shiratori, "Polishing of Silicon Single Crystals with an Elastic Wheel," Annals of the CIRP, Vol. 23, No. 1, 1974, pp. 103-104.
[15] Z. Pluta and K. Woźniak, "Some Aspects of Manufacture and Use of Abrasive Tools of Porous Elastic Bonds," Postępy Technologii Maszyn i Urzqdzeń, Vol. 7, No. 3, 1983, pp. 39-56.

[16] K. Woźniak, "Manufacture of Elastic Abrasive Tools of Polyurethane Bonds," Chemik, Vol. 35, No. 11-12, 1982, pp. 137- 141.

[17] Z. Pluta, "Effect of Machining Parameters using Elastic Grinding Wheels on the Surface Quality," Werkstatt und Betrieb, Vol. 7, No. 6, 1988, pp. 487-489.

[18] Z. Pluta and K. Woźniak, "Cutting Ability with Abrasive Grains Obtained from Post-Copper Slag," Werkstatt und Betrieb, Vol. 121, No. 10, 1988, pp. 843-847.

[19] W. Kacalak and Z. Pluta, "Grinding and Polishing Using Elastic Abrasive Wheels," Schleifen und Trennen, Vol. 107, No. 2, 1983, pp. 7-11.

[20] S.-S. Cho, Y.-K. Ryu and S.-Y. Lee, "Curved Surface Finishing with Flexible Abrasive Tool," International Journal of Machine Tools Manufacture, Vol. 42, No. 2, 2002, pp. 229-236. doi:10.1016/S0890-6955(01)00106-7

[21] S. Makuch and W. Kacalak, "The Elastic Properties of the Flexible Grinding Tools with Polyurethane Bonds," Advances in Manufacturing Science and Technology, Vol. 30, No. 1, 2006, pp. 89-99.

[22] Z. Pluta and T. Hryniewicz, "Verification of Forecasts on Surface Finishing Results of Peripheral Smoothing," International Journal of Advanced Manufacturing Technology, Vol. 42, No. 5-6, 2009, pp. 515-522. doi:10.1007/s00170-008-1616-0

[23] Z. Pluta and T. Hryniewicz, "Initial Cutting Conditions by Abrasive Grain Fixed Flexibly," International Journal of Advanced Manufacturing Technology, Vol. 43, No. 5-6, 2009, pp. 440-448. doi:10.1007/s00170-008-1722-Z

[24] Z. Pluta, "Butt-Mounted Elastic Wheel," Utility Pattern RP No. 55144, 1997.

[25] Z. Pluta, "Mounting to Fix Flat Abrasive Wheels of High Susceptibility," Patent RP No. 171852, 1997.

[26] Z. Pluta and A. Markiewicz, "Elastic Wheels," Utility Pattern RP No. 53832, 1996.

[27] Z. Pluta, "The Way and Device to Smooth External Rotary Surface with a Disk-Type Grinding Wheel of High Susceptibility," Patent RP No. 168170, 1996.

[28] Z. Pluta, "The Effect of Bond Kind on Some Properties of Elastic Wheels," Mechanik, Vol. 64, No. 3, 1991, pp. 110-116.

[29] K. Woźniak and Z. Pluta, "Use of Elastic Abrasive Wheels of Post-Copper Slag to Polish Colour Metals," Werkstatt und Betrieb, Vol. 120, No. 1, 1987, pp. 55-58.

[30] Z. Pluta and K. Woźniak, "The Effect of Machining Parameters on the Surface Roughness Smoothed by the Grinding Wheels of Porous Elastic Bonds," Postępy Technologii Maszyn i Urzqdzeń, Vol. 11, No. 1-2, 1987, pp. 45-58.

[31] Z. Pluta and T. Hryniewicz, "Advanced Model of the Tool Edge Blunting under Machining," International Journal of Advanced Manufacturing Technology, Vol. 51, No. 1-4, 
2010, pp. 35-43. doi:10.1007/s00170-010-2595-5

[32] K. Mańczak, “Technique of Experiment Planning," WNT, Warszawa, 1976.

[33] H. Szydłowski, “Theory of Measurements," PWN, Warszawa, 1978.
[34] E. B. Wilson Jr., "Introduction to Scientific Studies," 2nd Edition, PWN, Warszawa, 1968.

[35] W. E. Deming, "Statistical Adjustment of Data," Wiley, New York, 1938.

\section{List of More Important Notations}

$a_{f}$-in-feed

$v_{p}$ - velocity in the feed motion

$v_{s}$-peripheral velocity of the grinding wheel

$q_{v}$-velocity quotient

$k_{0}$-initial coefficient of intensity of the growth of measure of the surface roughness

$R_{a}$ - surface roughness measure (mean arithmetic profile deviation from the mean line)

$\Theta-$ nominal quotient constant

$\Theta^{*}$-real quotient constant

$(B S P F)_{R_{a}}^{0}$ —bottom roughness stable potential field

$(T S P F)_{R_{a}}^{0}$-top roughness stable potential field

$(A P F)_{R_{a}}^{1}$ —roughness unstable potential field

$(N P F)_{R_{a}}$-nominal roughness potential field

$(S P F)_{q_{v}}^{0}$ —quotient stable potential field

$(A P F)_{q_{v}}^{1}$-quotient unstable potential field 